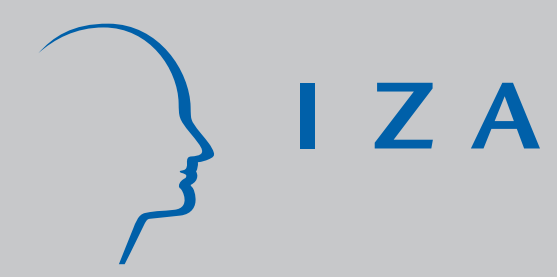

IZA DP No. 1212

Dynamics of Labour and Capital Adjustment A Comparison of Germany and the Netherlands

Michael Polder

Sher Verick

J uly 2004 


\title{
Dynamics of Labour and Capital Adjustment - A Comparison of Germany and the Netherlands
}

\author{
Michael Polder \\ Maastricht University \\ Sher Verick \\ IZA Bonn and University of Bonn
}

Discussion Paper No. 1212

July 2004

IZA

P.O. Box 7240

53072 Bonn

Germany

Phone: +49-228-3894-0

Fax: +49-228-3894-180

Email: iza@iza.org

Any opinions expressed here are those of the author(s) and not those of the institute. Research disseminated by IZA may include views on policy, but the institute itself takes no institutional policy positions.

The Institute for the Study of Labor (IZA) in Bonn is a local and virtual international research center and a place of communication between science, politics and business. IZA is an independent nonprofit company supported by Deutsche Post World Net. The center is associated with the University of Bonn and offers a stimulating research environment through its research networks, research support, and visitors and doctoral programs. IZA engages in (i) original and internationally competitive research in all fields of labor economics, (ii) development of policy concepts, and (iii) dissemination of research results and concepts to the interested public.

IZA Discussion Papers often represent preliminary work and are circulated to encourage discussion. Citation of such a paper should account for its provisional character. A revised version may be available on the IZA website (www.iza.org) or directly from the author. 


\section{ABSTRACT}

\section{Dynamics of Labour and Capital Adjustment - A Comparison of Germany and the Netherlands*}

In this paper we investigate the dynamic adjustment of labour and capital in German and Dutch firms. The Dutch labour market is characterised by greater flexibility in wages and work arrangements in comparison to Germany. These institutional differences imply that employment dynamics in the two countries should differ, and in particular, labour adjustment in the Netherlands should be more responsive to economic changes. On the other hand, there is unlikely to be such a divergence in capital dynamics as investment conditions are similar. Our results are consistent with this hypothesis. Furthermore, there is no evidence that labour market regulations in the two countries affect the dynamics of capital adjustment.

JEL Classification: C23, E22, E24

Keywords: investment, labour demand, interrelation, panel data, GMM

Corresponding author:

Sher Verick

IZA Bonn

P.O. Box 7240

53072 Bonn

Germany

Email: verick@iza.org

\footnotetext{
* Verick thanks IZA and the Deutsche Forschungsgemeinschaft for financial support. Polder would like to thank IZA, in particular Hielke Buddelmeyer, for its hospitality and financial support during his visit. We are indebted to our thesis supervisor Gerard Pfann for substantial discussion and comments. In addition, we would like to thank Manuel Arellano, Frank Windmeijer, and participants in the EEASS 2003 at IFS, and the brown-bag seminar series at IZA. The data used in this paper are collected by the Center for Research of Economic Microdata (CEREM) at Statistics Netherlands (CBS) and Centre for European Economic Research (ZEW). We thank our respective contacts for their kind cooperation. The views expressed in this paper are our own and do not necessarily reflect the views of the CBS or ZEW. Any remaining errors are our own.
} 


\section{Introduction}

The ability for firms to adjust employment and capital is influenced by institutional arrangements and government policies such as labour market regulation, unionisation and taxation. This implies that the dynamics of factor adjustment varies between countries where such constraints differ. For example, in a country with high firing costs we expect lower adjustment rates of labour than in a country where such costs are not present. ${ }^{1}$ A cross-country comparison of firms can therefore yield insights into the influence of these differences on the dynamics of labour and capital adjustment at the micro-level. In this paper we make such a comparison between Dutch and German manufacturing firms.

As neighbouring countries in the European Union, Germany and the Netherlands face in some respects similar economic conditions. However, in the last decade there has been a considerable divergence in their respective labour markets. Unemployment in Germany is now twice as high as it is in the Netherlands, a reversal from the 1980s. Wage stability and flexible work arrangements have helped the Netherlands achieve this and implies that labour adjustment should be more responsive to economic shocks in comparison to that in Germany. The conditions for capital adjustment are not so different as both countries face a similar structure of credit and monetary conditions as imposed by the European Central Bank, though there is some variation in tax policies. However, considering that factor demand decisions are likely to be interrelated, the differences in the labour markets may also translate to capital adjustment. Given this background, the empirical focus of the paper is to investigate capital and labour adjustment by firms in the Netherlands and Germany, and whether there is evidence that the institutional differences are reflected in the firm-level decisions regarding dynamic factor demand.

In the last decade or so a large theoretical literature on dynamic factor demand has developed, which has been complemented more recently by empirical evidence using firm-level data. ${ }^{2}$ Using such micro-data reveals the importance of

\footnotetext{
${ }^{1}$ The theoretical model of Bertola (1999) illustrates the negative impact of dismissal costs on both hirings and firings, though the net effect is ambiguous and depends on functional form assumptions.

${ }^{2}$ See Hamermesh and Pfann (1996) and Bond and Van Reenen (2002) for an overview of
} 
non-linearities in factor adjustment, which contradicts the assumption of linearquadratic adjustments typically relied upon in earlier studies. ${ }^{3}$ Common theoretical arguments for this behaviour are non-convexities in the adjustment costs and (partial) irreversibility. Most of these studies focus on investment using a univariate specification implicitly assuming labour to be fully flexible; see for example, Barnett and Sakellaris (1998), Cooper, Haltiwanger, and Power (1999) and Nilsen and Schiantarelli (2003). However, this assumption is not consistent with the institutional constraints in labour markets, which are evident in countries like the Netherlands and Germany. In strongly regulated labour markets, labour adjustment costs are not negligible and may even be higher than for capital. Thus, rather than assuming that capital is adjusted less frequently than labour, the relative adjustment rates of these factors should be tested and investigated empirically.

In addition, factor adjustment costs at the firm-level are possibly interrelated, which means that the adjustment of one factor affects the adjustment costs of another. For example, a firm may hire workers prior to investing in some new technology. By doing so, it reduces the costs of adjustment for capital since the firm is able to integrate the technology and bring it to full productivity faster than would have been the case without these new workers. This type of interrelation between capital and labour adjustment would imply a positive correlation between investment in the current period and labour adjustment in the previous period.

Interrelation was first addressed in a linear setting using sector-level data by Nadiri and Rosen (1969), though this was not based on a structural model with adjustment costs. Shapiro (1986) expands upon Nadiri and Rosen (1969) and estimates a structural dynamic model of factor demand derived from the Euler equations. More recently, Merz and Yashiv (2003) investigate the impact of labour on the market value of the firm using a production-based asset pricing model with frictions in the adjustment of both capital and labour. In this model, the interrelation between the two factors is a key determinant of the market value

\footnotetext{
this topic.

${ }^{3}$ For an early exposition of a symmetric convex adjustment cost function, see the seminal contribution of Eisner and Strotz (1963).
} 
of the firm. However, this paper also restricts the analysis to sector-level data and only considers the relation between gross investment and hirings. Perhaps surprisingly, the issue of interrelation has not been investigated empirically in the context of non-convex adjustment costs. ${ }^{4}$ Evidence of such costs are not reflected in sector-level data as investment and employment changes are smoothed by aggregation. Thus, firm-level data is required to explore such behaviour.

We contribute to this literature by considering a model where capital and labour adjustment are subject to both convex and non-convex adjustment costs. The adjustment cost framework is used to derive a structural model and provides the basis for our empirical strategy. We use firm-level data for Germany and the Netherlands to estimate our dynamic models of investment and labour adjustment. Given that the German labour market is less flexible in terms of temporary workers, we expect that employment adjustment is more frequent in the Netherlands. Furthermore, we allow for the possibility of interrelation in the adjustment costs. Interrelation allows for the differences in adjustment of labour to translate to the dynamics of investment.

In Section 2 we compare the institutional structures in Germany and the Netherlands and their implication for the dynamic adjustment of labour and capital by firms in these countries. In Section 3 we discuss estimation and identification issues. The data is described in Section 4, while the results are presented in Section 5, which includes a discussion about sample selection bias. Finally, we conclude in Section 6.

\section{Institutional Background}

To understand the similarities and differences of capital and labour adjustment in Germany and the Netherlands, it is useful to briefly describe their economies and institutional structures and how this should be reflected in dynamic factor

\footnotetext{
${ }^{4}$ See Dixit (1997) and Eberly and Mieghem (1997) for a theoretical account in a model with kinked-linear adjustment costs. Some empirical studies allow for more general adjustment costs structures with multiple quasi-fixed factors while distinguishing between different types of labour, see for example Pfann and Palm (1993), and Alonso-Borrego (1998). Sakellaris (2004) and Letterie, Pfann, and Polder (2004) find that there is a statistical relationship between the adjustment dynamics of an input factor and the incidence of an adjustment spike in another factor.
} 
demand. In general, the economies of these two countries have been characterised as having significant levels of government intervention and coordination between the government, employers and unions. This has been called the "Rheinland model" in contrast to the "Anglo-Saxon model" which is still used to describe the economies of the UK and the USA (Delsen and de Long 1998). Germany and the Netherlands have many institutional similarities such as their social welfare systems and in particular, as a result of harmonisation of policies in the European Union. Nonetheless, in the last decade or so there has been a divergence in their economies, which should translate to differences in the dynamics of factor adjustment in the two countries.

Firstly, as seen in Table 1 in Appendix A, since the mid-1990s the economy of Netherlands as represented by the growth rate in GDP (at market prices) has grown faster than that of Germany. However, this difference is largely due to sectoral composition as the service sector is larger in the Netherlands, while the manufacturing sector is more dominant in Germany. As shown in the second part of Table 1, the manufacturing sector in Germany has actually performed better than its Dutch counterpart in some of the years of the late 1990s, which may result in higher rates of factor adjustment in German firms during this period.

As also displayed in the third section of Table 1, from 1992 to 2000 there was negative growth in employment in German industry, which indicates that there was a severe contraction in this sector and that the layoffs continued when the sector recovered during 1997 to 2000. In contrast, employment in the Dutch industrial sector decreased from 1992 to 1996 and then started increasing at a small rate. Thus, the macro data suggests that there was considerable restructuring in both countries, particularly in Germany, and this should be reflected in the dynamics of factor adjustment. Related to this situation, Germany has been suffering from a persistently high unemployment rate since the mid-1990s. As of 2001, unemployment in Germany stood at $7.9 \%$ in comparison to $2.4 \%$ in the Netherlands, a reversal of the situation a decade before. The growth in Dutch employment over this period has mainly come from the service sector, and resulted in particular from the increase in part-time jobs which accounted for $42.2 \%$ of total employment in 2001. In contrast, there has not been a similar growth in part-time work in the German labour market; as of 2001 , only $20.3 \%$ 
of total employment were part-time jobs. ${ }^{5}$ A reason for the high percentage of part-time workers in the Netherlands is the higher participation rate of women.

As argued in this paper, there are some differences in the labour market institutions of the Netherlands and Germany that could influence how firms adjust employment. Firstly, the much quoted study of OECD (1999) provides a ranking of countries based on indicators of the relative strictness of employment protection legislation. According to this study the Netherlands has slightly stricter legislation for regular workers, but temporary employment is far more flexible than in Germany. Given that Dutch firms are more able to use these type of workers in response to changes in economic conditions, we expect that employment adjustment is more frequent in the Netherlands. Another relevant issue in this context is the relative weakness of the unions in the Netherlands in comparison to Germany, which enabled the adoption of more flexible working arrangements by Dutch employers. In particular, during the post-unification years there was considerable wage inflation in Germany as the result of wage demands by unions, which was not evident in the Netherlands. This led to an increase in labour costs between 1991 and 1995 in Germany by 3.2\% in comparison to only $0.6 \%$ in the Netherlands. As a consequence, there was a loss of competitiveness for German industry, which in addition to the appreciation of the exchange rate, contributed to a fall in exports, an important source of revenue for both economies. In contrast to Germany, real wages have been decreasing in the Netherlands helping increase exports and growth of the economy (Delsen and de Long 1998).

With regards to the influence of institutional structures in the two countries on the dynamics of investment, the differences are less obvious. Firstly, while there are some aspects of the capital markets which vary in Germany and the Netherlands, they are more alike than in comparison to the Anglo-Saxon system. Secondly, monetary policy is determined at the European Union level and the similar structure of the credit market implies that monetary transmission should not differ significantly. Thirdly, since 1992 the currencies in the European Union have fixed exchange rates. Finally, companies in both countries tend to finance their investments from internally generated funds (Hoogduin and Huisman 1998).

Besides the higher growth rate in German manufacturing, these macroeco-

\footnotetext{
${ }^{5}$ See Eurostat Yearbook 2002.
} 
nomic and institutional issues suggest that we expect to see higher rates of labour adjustment in the Netherlands. In terms of capital adjustment, it is not clear a priori how the rates of investment should differ between the two countries. If labour adjustment and investment are interrelated, then differences in labour market flexibility also translate to capital adjustment.

\section{Econometric Model and Identification}

To derive the econometric specification, we solve a dynamic optimisation problem where firms maximize their net present value at the beginning of period $t$ with respect to labour and capital. Initially we ignore the role of non-convexities in adjustment costs, though we return to this important issue in Sections 4 and 5. Hence, under the assumption of convex adjustment costs for both factors, this yields two linear dynamic first-order conditions, or Euler equations, including expectation terms for period $t+1$. Assuming rational expectations, these equations can be used as a basis for Generalized Method of Moments (GMM) estimation as first proposed by Hansen (1982) and later extended to efficient panel data estimators by such studies as Arellano and Bond (1991) and Blundell and Bond (1998). The optimisation problem can be represented as the following Bellman's equation (cf. for example Bond and Meghir (1994))

$$
\begin{aligned}
V\left(A_{t}, K_{t-1}, L_{t-1}\right)=\max _{\left\{I_{t}, H_{t}\right\}}[ & F\left(A_{t}, K_{t}, L_{t}\right)-w_{t} L_{t-1} \\
& \left.-A C\left(K_{t}, I_{t}, L_{t}, H_{t}\right)+\beta E_{t} V\left(A_{t+1}, K_{t}, L_{t}\right)\right],
\end{aligned}
$$

which is subject to the equation of motion $K_{t}=(1-\delta) K_{t-1}+I_{t}$, where $\delta$ is a constant discount rate. $A_{t}$ is a strictly-exogenous Markov process that captures productivity and technology shocks in period $t, K_{t}$ is the capital stock, $L_{t}$ is the number of workers employed, and $I_{t}$ is total investment. Since only net employment changes are observed, labour adjustment is denoted by $H_{t}=L_{t}-L_{t-1}$. Note that capital and labour are assumed to become immediately productive. Finally, $w_{t}$ is the wage rate. The production function is assumed to be Cobb-Douglas 


$$
\begin{aligned}
Y_{t} & =F\left(A_{t}, K_{t}, L_{t}\right) \\
& =A_{t} K_{t}^{\alpha_{K}} L_{t}^{\alpha_{L}}
\end{aligned}
$$

and the adjustment costs function is given by

$$
A C\left(K_{t}, I_{t}, L_{t}, H_{t}\right)=p_{t} I_{t}+\frac{v}{2}\left(\frac{I}{K}\right)_{t}^{2} K_{t}+w_{t} H_{t}+\frac{\gamma}{2}\left(\frac{H}{L}\right)_{t}^{2} L_{t}+\vartheta I_{t} H_{t}
$$

where $p$ is the price of capital goods, and $v, \gamma$, and $\vartheta$ are adjustment cost parameters. The first term $p_{t} I_{t}$ represents the direct cost of capital, while the second term $\left(\frac{I}{K}\right)_{t}^{2} K_{t}$ is included to capture strictly convex costs of investment which result from disruptions to production and other forms of internal adjustment costs. This implies that firms have an incentive to spread investment over time to avoid increasing marginal costs. Similarly, labour costs include the wages paid to the net change in employment, which can be positive or negative, in addition to a strictly convex component which is increasing in the labour adjustment rate. We are assuming here that adjustment costs are symmetric for negative and positive changes to employment. Finally, the last term in the adjustment costs specification (3) captures the interrelation between capital and labour adjustment costs. Compared to an interaction term with rates, this specification has the advantage that it yields a more tractable estimating equation. We return to the validity of this assumption in Section 5. As argued in this paper, firms also incur fixed costs when adjusting capital or labour, which are not specified in (3). However, our assumption of convex adjustment costs remains valid as we condition on the optimality of non-zero adjustment. Fixed costs only have an impact on the decision to adjust, but conditional on adjustment, the convex costs determine the level of factor demand. As discussed at the end of this section, this implies that the optimality conditions derived here apply only to a subsample of the data.

Given the production function (2) and the adjustment cost function (3), we can derive the following system of Euler equations by solving (1) 


$$
\begin{aligned}
p_{t}+v\left(\frac{I}{K}\right)_{t}-\frac{v}{2}\left(\frac{I}{K}\right)_{t}^{2} & +\vartheta H_{t}-\alpha_{K}\left(\frac{Y}{K}\right)_{t} \\
& =(1-\delta) \beta E_{t}\left(p_{t+1}+v\left(\frac{I}{K}\right)_{t+1}+\vartheta H_{t+1}\right) \\
w_{t}+\gamma\left(\frac{H}{L}\right)_{t}-\frac{\gamma}{2}\left(\frac{H}{L}\right)_{t}^{2} & +\vartheta I_{t}-\alpha_{L}\left(\frac{Y}{L}\right)_{t} \\
& =(1-\rho) \beta E_{t}\left(w_{t+1}+\gamma\left(\frac{H}{L}\right)_{t+1}+\vartheta I_{t+1}\right) .
\end{aligned}
$$

The Euler equations, (4) and (5), have the standard interpretation as intertemporal optimality conditions: firms adjust their factors of productions such that the marginal adjustment cost less the marginal product of the factor in period $t$ (left-hand side) is equal to the discounted expected value of the marginal adjustment cost in period $t+1$ (right-hand side). The expectations in the Euler equations (4) and (5) are unobserved. Nevertheless, they can be replaced with their realisations, which under the assumption of rational expectations introduces a forecast error that is orthogonal to all variables in the information set at the time of the decision. Making this substitution, and mapping the structural parameters into the reduced form, the following econometric specifications for investment and labour adjustment are obtained

$$
\begin{aligned}
\left(\frac{I}{K}\right)_{i t}= & \tau_{1}\left(\frac{I}{K}\right)_{i, t-1}+\tau_{2}\left(\frac{I}{K}\right)_{i, t-1}^{2}+\tau_{3}\left(\frac{Y}{K}\right)_{i, t-1} \\
& +\tau_{4} p_{i t}+\tau_{5} p_{i, t-1}+\tau_{6} H_{i t}+\tau_{7} H_{i, t-1}+\epsilon_{i t}^{I} \\
\left(\frac{H}{L}\right)_{i t}= & \theta_{1}\left(\frac{H}{L}\right)_{i, t-1}+\theta_{2}\left(\frac{H}{L}\right)_{i, t-1}^{2}+\theta_{3}\left(\frac{Y}{L}\right)_{i, t-1} \\
& +\theta_{4} w_{i t}+\theta_{5} w_{i, t-1}+\theta_{6} I_{i t}+\theta_{7} I_{i, t-1}+\epsilon_{i t}^{H} .
\end{aligned}
$$

The technology and cost parameters can in principle be recovered from the non- 
linear relations between the reduced-form and structural parameters using a Minimum Distance procedure. However, the focus in this paper is on the estimation of the reduced-form results for the German and Dutch samples, which still allows for a comparison of state dependence in the dynamics and how responsive investment and labour adjustment are to economic variables in these two countries and whether there is any evidence of interrelation. Note that $H_{i t}$ and $H_{i, t-1}$ enter the investment equation (6), whereas $I_{i t}$ and $I_{i, t-1}$ enter the labour adjustment equation (7), to capture possible interrelation among the adjustment decisions.

The error terms are specified such that $\epsilon_{i t}^{j}=\mu_{i}^{j}+u_{i t}^{j}$, where $j \in\{I, H\}$, and $\mu_{i}^{j}$ is a firm-specific and $u_{i t}^{j}$ an idiosyncratic error term. Time-specific effects can be modelled by including year dummies. Estimation is complicated by the presence of the nuisance parameter $\mu_{i}^{j}$ which is correlated with the lagged dependent variable and endogenous or predetermined explanatory variables. Equations (6) and (7) are first-differenced to eliminate the fixed-effect; however, the differenced dependent variable (and possible endogenous or predetermined explanatory variables) are still correlated with the differenced error term $\Delta \epsilon_{i t}^{j}$, but can now be instrumented with suitable lags of the corresponding levels. ${ }^{6}$ This results in the estimator proposed by Arellano and Bond (1991).

However, first-difference GMM estimators such as Arellano and Bond (1991) have been found to have poor finite sample properties when the lagged levels are weak instruments for the differenced variables. As discussed in Blundell and Bond (1998) and Arellano and Bover (1995), it can be shown that under the assumption of stationarity, lagged differences of the variables in the levels equation are uncorrelated with the fixed effect. This yields additional moment restrictions for GMM estimation. The use of both the moment restrictions based on the differenced specification as well as those resulting from the levels equation leads to the so-called System GMM estimator.

Another issue that has been explored by the empirical literature is the importance of non-convex adjustment costs and partial irreversibility. ${ }^{7}$ Both these

\footnotetext{
${ }^{6}$ This is appropriate if the untransformed error term is serially uncorrelated, which can be tested for. For endogenous variables, $t-2$ and earlier lags are valid instruments, while for predetermined variables we can use $t-1$ and earlier. Exogenous variables can instrument themselves.

${ }^{7}$ For non-convexities in investment see for example Cooper, Haltiwanger, and Power (1999),
} 
features lead to zero-adjustment 'regimes' where firms do not adjust factor levels. However, the Euler equations are intertemporal marginal conditions of optimality and are derived under the assumption that adjustment is optimal in adjacent periods, and hence, are invalid when there is zero adjustment. Nevertheless, the Euler equations remain valid if firms adjust in two consecutive periods, which implies that the estimation of equations (6) and (7) needs to be restricted to the subsample where firms adjust in two adjacent years. Moreover, since the decision to adjust factor levels in these models is endogenous, using the subsample where adjustment is non-zero for estimation is likely to result in biased estimates. Firms with higher adjustment costs are less likely to adjust, hence, estimates of adjustment costs should be biased downwards when using the subsample where adjustment is non-zero. In Section 4 we present some summary statistics with respect to the different adjustment regimes which provides evidence of the extent of censoring and how this is correlated between investment and labour adjustment. In Section 5 we investigate the impact of sample selection bias on the estimation results.

\section{Data and Summary Statistics}

To ensure that the results reflect underlying economic differences, two comparable datasets are used that span the period from 1992 to 2000. The German data is sourced from the Mannheim Innovation Panel (MIP) and the Dutch data consist of a combination of data sources from Statistics Netherlands. The German dataset is at the firm-level consisting of mostly single location operations, while the Dutch data is at the plant-level. The MIP is collected by the Centre for European Economic Research (ZEW) in Mannheim, Germany, which commenced a survey of German firms in 1993. ${ }^{8}$ The MIP was initiated as part of the EU Community Innovation Surveys hence its focus on innovation at the firm-level. The sample of the MIP is based on a stratified random sample and firms participate

Abel and Eberly (2001), Nilsen and Schiantarelli (2003), and Letterie and Pfann (2003). Nonconvex costs of adjustment have also been incorporated into models of labour adjustment, see for example Hamermesh (1989).

${ }^{8}$ The MIP is retrospective such that the 1993 survey requests information for 1992. See www.zew.de and Janz, Ebling, Gottschalk, and Niggemann (2001) for more information. 
voluntarily in the survey. On average, between 2000 and 2500 firms respond each year, though attrition rates have been high. The Dutch data is administered by Statistic Netherlands (CBS) at the Center for Research of Economic Microdata (CEREM) and the sample used in this paper is a linked dataset which combines the Investment Statistics (IS) and the Production Statistics (PS). The samples used in estimation consist exclusively of firms in the manufacturing sector. ${ }^{9}$ Both datasets provide information on annual investment, though this is restricted to nonnegative values, employment level and sales. Furthermore, a measure for the capital stock is available in the MIP and this is used in the first year as a starting value, with capital for the remaining years constructed using the perpetual inventory method. In the case of the Dutch data, a measure for capital stock is not available. Therefore, for each firm the first five years of reported investment (starting in 1987) are used to construct a capital stock proxy as described in Letterie and Pfann (2003). In terms of employment, since only levels are observed, we are restricted to use net employment changes as a decision variable. Furthermore, we focus on total employment as full and part-time workers are not separately identified in the Dutch data. Finally, two-digit sector-level price information is employed to convert nominal to real quantities; investment and capital stock are deflated by the price index for investment goods, and sales are deflated by the producer price index. ${ }^{10}$

First, we consider the statistics summarising the data, which provides us a preliminary indication of sample characteristics, and in particular, of the rates of capital and labour adjustment. As seen in Table 2 in Appendix A, the average (median) annual investment for German firms is 8 (0.8) million Deutsche Mark (DM), and for their Dutch counterparts it is considerably lower at $2.9(0.44)$ million Dutch guilders (NLG). ${ }^{11}$ The data also shows that the German firms are on average larger in terms of employment and sales, though the medians are more comparable. The investment statistics translate to an average (median) annual investment rate of $18.0 \%$ (12.5\%) for German firms and 6.8\% (4.4\%) for Dutch

\footnotetext{
${ }^{9}$ The sample consists of establishments in sectors $15-36$ as according to the NACE Rev. 1 classification.

${ }^{10}$ See the German Statistical Office, www.destatis.de, and the CBS, www.cbs.nl, for more information regarding the German and Dutch sector-level time series data.

${ }^{11}$ The conversion rate is about $1 \mathrm{DM}=1.10 \mathrm{NLG}$.
} 
firms. The higher investment rates in the German data are also consistent with the higher growth rates of the manufacturing sector in Germany as displayed in Table $1 .{ }^{12}$ The labour adjustment rate is slightly below zero for both countries, showing that on average German and Dutch firms have been downsizing in terms of employment over this period. ${ }^{13}$ The summary statistics show that the average capital productivity is higher in German firms, while the average labour productivity is higher in the Dutch sample. Differences in the sectoral distribution may be one cause of this variation in the average factor productivity. In the German sample, the largest sector is the machinery industry with around $18 \%$ of observations followed by the metal products and rubber and plastic goods industries with around $12 \%$ and $8 \%$, respectively. In the Dutch sample, the machinery and metal products are the main industries, with $14 \%$ and $15 \%$ of the observations. However, the food industry and publishing and printing are also strongly represented with $13 \%$ and 10\%. Finally, the labour costs per worker in both countries are roughly the same.

In Figures 1 and 2 we compare the distribution of the investment rate for the German and Dutch samples. Consistent with the summary statistics, the observations in the Dutch sample are much more concentrated at the lower end than is the case with the German data, which are more dispersed. As illustrated in Figures 3 and 4, both distributions for the labour adjustment rate are centred around zero but in the German case the observations are again somewhat more dispersed.

To get an indication of the importance of censoring in capital and labour adjustment we look at the percentage of observations where firms do not adjust factors. Table 3 in Appendix A indicates that for the German data, almost 10\% of investment observations are censored such that investment is zero. In the case of labour adjustment, the rate of censoring is higher: over 15\% of observations in the German panel are firms not adjusting their employment. In comparison, Dutch firms adjust capital more often with only about $4 \%$ of observations where investment is zero. Surprisingly, labour adjustment is carried out less frequently

\footnotetext{
${ }^{12}$ However, the difference in the construction of a capital stock measure could also play a role here.

${ }^{13}$ We drop outliers for the sample used in estimation where the labour adjustment rate is below $-100 \%$ and other observations which were deemed to be exceptional.
} 
in the Dutch sample with about $18 \%$ of observations for non-zero adjustment.

These results are primary evidence that firms adjust capital stock more often than their employment levels, which in terms of the literature on non-convex adjustment costs, implies that this type of adjustment costs are higher for labour than for capital. This is contrary to what is typically assumed in theoretical models where labour is fully flexible and capital is (quasi-)fixed. The differences in censoring are so large that this claim is likely to remain valid even if we were able to observe gross employment flows. Along with the findings from Figures 1 - 4, it follows that Dutch firms carry out smaller investments but invest more frequently. In terms of adjustment costs, this can be explained by higher fixed costs for German firms, or that Dutch firms face larger convex costs so that it is beneficial to spread investment over time.

On the other hand, labour adjustments in the Dutch data are also smaller but occur less frequently than in the German data. This runs counter to the idea that the German firms are less flexible with respect to employment adjustment as argued above in Section 2. However, as already noted in that section, the availability of part-time and temporary workers plays an important role in the Netherlands. This helps the Dutch firms adjust their workforce without hiring or firing permanent employees. These types of secondary workers cannot be identified in our annual data. In addition, the rate of censoring in the Dutch case is driven by a high percentage of zero adjustment in 1995 to 1997 where it reaches $25 \%$ of observations. The average for the other years is around $13 \%$. In comparison, the rate of censoring in the German data is relatively constant over this period.

As was mentioned in Section 3, the estimation sample for the Euler equations only consists of those observations where firms adjust in two consecutive periods. Table 3 provides the percentage of observations that are censored in this way. For the investment equation this is up to $10 \%$ for Germany, but only about $6 \%$ for the Netherlands. In the labour equation almost $27 \%$ of the observations is censored in the German case, and similarly around $30 \%$ for the Netherlands. The bias resulting from this sample selection is discussed in further detail in Section 5.4 .

Another interesting aspect of the raw data is how firms adjust capital and 
labour together. If both factors face non-convex adjustment costs or are partially irreversible, this leads to a number of possible adjustment regimes, as in Dixit (1997) who specifies a model with kinked-linear adjustment costs. In Table 4 the observations of the German and Dutch samples are allocated to different regimes based on the adjustment of factors. The similarity of the distribution over the regimes between the two samples is striking. As can be seen from Table 4 the proportion of cases where firms adjust both capital and labour is about $80 \%$ of observations in both the Germany and Dutch samples. This shows that adjustment is mostly simultaneous in both cases, which supports the argument of interrelated adjustment in our theoretical model, possibly due to cost efficiencies. Furthermore, for both the German and Dutch data we see that there is some heterogeneity with respect to the direction of labour adjustment when firms invest. Given that a firm invests, negative labour adjustment is slightly more likely than positive adjustment to employment. Thus, firms invest while simultaneously downsizing their workforce. This heterogeneity is also reflected in the observations where firms do not invest but adjust employment, though this occurs much less frequently. Finally, in only around $1 \%$ of observations are firms not adjusting either capital stock or employment. This means that in both samples firms almost always adjust the capital stock and/or the employment level.

\section{Results}

The investment and labour adjustment equations (6) and (7) are estimated separately using the subsample where firms make non-zero adjustments to capital and employment in two adjacent periods. We implement the Blundell-Bond System GMM estimator for dynamic linear panel data models (Blundell and Bond 1998), using Ox, version 3.30 (Doornik 2002)), and the DPD package, version 1.21 (Doornik, Arellano, and Bond 2002). ${ }^{14}$ Standard errors are robust to heteroskedasticity and corrected for finite sample bias (see (Windmeijer 2000)).

\footnotetext{
${ }^{14}$ We find that the Blundell-Bond System GMM estimator provides better identification than the Arellano-Bond estimator.
} 


\section{$5.1 \quad$ Investment equation}

The results for the investment rate equation (6) are displayed in Table 5 in Appendix A. In column (1) and (3) we report the estimates for the German and Dutch samples without controlling for sample selection bias. We return to the specification with the sample selection correction in Section 5.4.

For the German sample as denoted in column (1) of Table 5, the coefficient on the lagged dependent variable is positive and significant at the $1 \%$ level. This indicates that there is substantial positive state dependence in investment, which implies that German firms in the estimation sample tend to spread investment over a longer period. The quadratic term is negative and significant suggesting that the effect of last period's investment rate is positive but declining. The investment rate is increasing with the average product of capital in the previous period. In this specification, the price index for capital goods in both the current period and its lag are insignificant, which is likely to result from the lack of variation in the sector-level index. There is no evidence that the investment rate is correlated to changes with employment in the current and previous period. The Sargan test statistic does not reject the validity of the instruments, and there is no indication of second-order autocorrelation.

In column (3) of Table 5 we report the results for the Dutch sample. As with the German estimates, there is evidence of positive but declining state dependence, though the coefficients are of a smaller magnitude. This indicates that Dutch firms concentrate investment more than their German counterparts. As with the German firms, investment is increasing with the average product of capital in the previous period. In contrast to the German results, the coefficients on the price index for capital goods and its lag are significant at the 5\% level. They indicate that investment is negatively correlated with the current price but positively correlated with the price in the previous period, which suggests that firms delay investment to the current period when prices are higher in the previous one. Though not found in the German sample, there is evidence in the Dutch results of a positive relation between the investment rate and net employment adjustment in the previous period. However, the effect of this interrelation term on the investment rate is negligible. The validity of the instruments and the 
absence of second-order autocorrelation are again not rejected

As discussed in Section 2, we expect fewer differences in the investment conditions in the two countries. The results from columns (1) and (3) show that, while the investment behaviour is indeed similar, German firms spread their investments more. This indicates that German firms face higher convex adjustment costs for capital. The only significant interrelation term is the lagged employment change in the Dutch case, and all estimated coefficients for current and lagged employment changes are of a negligible magnitude. Hence, we find no evidence that changes in the employment level affect capital adjustment. Consequently, there is no indication that differences in employment dynamics between the two countries translate to investment.

\subsection{Labour adjustment equation}

The results for the labour adjustment equation (7) are displayed in Table 6 in Appendix A. As in the case of investment, in column (1) and (3) we report the estimates for the German and Dutch samples without controlling for sample selection bias.

The German results for the labour adjustment equation are listed in column (1) and indicate that in contrast to investment, there is evidence of negative state dependence. The interpretation for this could be twofold. One reason could be that German firms concentrate adjustments to employment in a short period of time. In terms of adjustment costs, this result is consistent with labour consisting of different types of workers with heterogeneous costs. In particular, the adjustment of permanent workers entails higher fixed costs and this results in periods of lumpy adjustment followed by ones where there are no changes to the number of permanent employees. In such periods, firms adjust only secondary workers which incur no or lower fixed costs of adjustment. Alternatively, the negative sign may result from a change in the sign of adjustment from one period to the next. The insignificance of the wage variables could reflect the wage rigidity due to the high degree unionisation in Germany. The coefficient on the current investment level is negative and significant at the $10 \%$ level, while the coefficient on the lagged variable is positive but not significant. Similar to the effects of 
interrelation in the investment equation, the size of the coefficients are very small. The negative sign is consistent with the high percentage of observations in the regime with $I / K>0$ and $H / L<0$ in Table 4 . The other coefficients are insignificant and therefore, according to these results, it is state dependence that largely drives current labour adjustment in German firms. The validity of the instruments and the absence of second-order autocorrelation are not rejected.

The estimates for the Dutch sample are compiled in column (3) of Table 6 and in contrast to the German results, there is evidence of positive state dependence. Hence, Dutch firms spread the adjustment of employment over time. Though not present in the German results, the coefficient on the per-worker wage in the current period is negative and significant. The sign reverses for the lagged wage, which implies that firms delay adjustment to employment to the current period when wages are higher in the previous one. The sign of the coefficients for the current and previous level of investment are the same as in the German sample, negative and positively, respectively, but only the lagged variable is significant. In line with the German results, the coefficient estimates are very small and imply that an increase in investment in the previous period has a positive but only marginal impact on the labour adjustment rate in the current period. There is no evidence of second-order autocorrelation. However, although the same instrument set is used as in the German specification, the Sargan test statistic points at a rejection of the validity of these instruments. To investigate if this rejection results from a particular instrument, we checked the sensitivity of the Sargan test statistic to various instrument sets and the rejection is found in all specifications. A reason for the rejection of the instrument validity could be sample selection bias, which is investigated in the next section.

Unlike the summary statistics in Section 4, these results illustrate that there is a clear difference between the labour adjustment in the two countries. The finding that labour adjustment is more responsive to changes in wages and investment is consistent with the more flexible labour market in the Netherlands versus the stricter regulations in Germany. In addition, it appears that German firms incur higher fixed costs. 


\subsection{Alternative specification for interrelation}

The identification of interrelation relies on the specifications of (6) and (7), and in particular, how interrelation enters the adjustment cost function equation (3). As presented in Section 3, the effect of interrelation on adjustment costs is assumed to be in levels, though the dependent variable is in rates. This may result in the variables that are supposed to capture interrelation to pick up some sort of scale effects. To check the validity of these assumptions, equations (6) and (7) are re-estimated using the rates for the interrelation terms instead of the variables in levels, though such a specification cannot be derived from a structural model. That is, the change in employment $H_{i t}$ in equation (6) is replaced by $(H / L)_{i t}$, and likewise, the investment rate $(I / K)_{i t}$ is used instead of the investment level $I_{i t}$ in equation (7).

In the investment equation, the German results suggest that the investment rate is positively and significantly related to both the labour adjustment rate in the current and previous period. ${ }^{15}$ Furthermore, the effects are much larger than the results in Table 5. This indicates, that firms adjust factors both sequentially and concurrently. However, these coefficients, though also positive, are not significant in the Dutch sample. Furthermore, while the coefficients on the investment rate in the current and previous periods are positive in the labour equation, they are insignificant in both the German and Dutch samples.

\subsection{Sample selection bias}

In this section we look at an econometric issue that has generally been ignored in this literature. As clear from the summary statistics in Section 4, in our datasets there are a significant number of observations where investment or labour adjustment is zero. Furthermore, in estimating equations (6) and (7), we only use those observations where a firm adjusts its level of an input factor for two consecutive periods. As discussed in Section 3, this introduces the problem of sample selection since the event on which we are conditioning is endogenous. To assess the sensitivity of our results to this bias we follow Aguirregabiria (1997) and Alonso-Borrego (1998) and estimate the Euler equations using a two-step

\footnotetext{
${ }^{15}$ Results are not reported here but are available from the authors on request.
} 
approach similar to the sample selection model of Heckman (1979). This approach involves the estimation of a probit model for both investment and labour adjustment in a first-stage, where the dependent variable is a binary indicator that equals one when adjustment of capital or labour is non-zero in two consecutive years and zero otherwise. From the first-stage estimates, correction terms are constructed as per Heckman's two-step estimator. These correction terms are an estimate of the additive bias which is the (conditional) expectation of the respective error terms given selection. This additive bias may invalidate the orthogonality conditions used in the GMM estimation. Equations (6) and (7) are then estimated using this bias correction term as an additional regressor.

The results for the first-stage probit models for investment and labour adjustment are reported in Tables 7 and 8 in Appendix A. The independent variables are the same as those determining the size of the investment and labour adjustment rates in period $t$ and $t-1$ as per equations (6) and (7). Twice-lagged variables determine adjustment in period $t-1$ and are by assumption uncorrelated with the differenced error term $\Delta \epsilon_{i t}^{j}$, and hence serve as natural exclusion restrictions in period $t$. As shown in Tables 7 and 8 , the adjustment rates and their squares in period $t-1$ are highly significant in all cases. The significance of the other variables differs between the specifications. Turning to the exclusion restrictions, in the investment selection equation as denoted by columns (1) and (2) in Table 7 , the twice-lagged squared investment rate and sales-capital ratio are significant in the German sample, while the twice-lagged investment rate, its square and the price of capital goods are significant in the Dutch specification. The lagged and twice-lagged price of capital goods are not included in the German specification as these variables are highly collinear with the price in the current period. In the labour adjustment selection equation as shown in columns (1) and (2) in Table 8 , the twice-lagged sales-worker ratio, wages and the investment level are significant in the German sample, while only the twice-lagged labour adjustment rate is significant in the Dutch specification. The significance of these exclusions restrictions is important in terms of identifying the selection bias in the estimation of the investment and labour adjustment equations (6) and (7). However, due to the definition of our binary dependent variable there is no natural interpretation of the coefficient estimates. 
Columns (2) and (4) in Table 5 list the results for the investment equation when the correction term is added as an additional variable for the German and Dutch samples. ${ }^{16}$ The selection term in the German sample is positive but not significant. Most parameter estimates go down, but all estimates are within one standard error of the initial ones. The correction term in the investment equation for the Netherlands is in contrast negative but also highly insignificant. The fact that all coefficients except the current price are insignificant in this specification, indicates a multicollinearity problem, an issue common to sample selection models. Nonetheless, for both samples there is no clear evidence that estimates are biased due to sample selection.

The results for the labour adjustment equation with correction for sample selection bias are denoted in columns (2) and (4) of Table 6. As in the case of investment, the coefficient on the correction term is positive and insignificant in the German sample. However, the coefficient is negative and strongly significant in the Dutch sample. Most of the results remain the same but interestingly the lagged dependent variable becomes insignificant while the average product becomes significant. This may result from collinearity of these variables with the correction term. The Sargan test statistic still leads to a rejection of the validity of the instruments used for the Dutch results. However, it is importantly lower than before suggesting that selection bias weakens the validity of the instruments.

\section{Conclusion}

How firms adjust employment and capital is influenced by institutional arrangements and government policies such as labour market regulation and unionisation. This implies that the dynamics of labour and capital adjustment should also vary between countries where such constraints and policies differ. Moreover, it has long been assumed that capital is adjusted less frequently than labour. This assumption seems to be inconsistent with the observed patterns of factor adjustment in countries where labour markets are subject to significant intervention such as in Germany and to a lesser extent, in the Netherlands. Thus, we would expect that

\footnotetext{
${ }^{16}$ Standard errors were not corrected for the use of predicted values but such a correction is unlikely to alter the above conclusions.
} 
the differences in labour market policies in Germany and Netherlands are also reflected in the adjustment of employment. Furthermore, factor adjustment costs at the firm-level are possibly interrelated which means that the adjustment of one factor affects the adjustment costs of another. This implies that the constraints on employment are translated to the investment dynamics.

To address these issues, we estimate dynamic investment and labour adjustment equations with interrelation between the two factors based on a structural model. The dynamic linear System GMM estimator of Blundell and Bond (1998) is implemented to take account of the endogeneity of variables. Moreover, we also address the impact of sample selection bias on estimates, an issue that has not been widely addressed in the literature.

Using Dutch and German firm-level data, we find that while the dynamics of investment are relatively similar in the two countries, the German firms spread their adjustments to capital over a longer period. Secondly, there is a clear difference in the dynamics of labour adjustment with the German firms exhibiting negative state dependence, while the labour adjustment rate of the Dutch firms is positively correlated to the adjustment in the previous period. The negative relationship in the German sample could be driven by higher fixed costs resulting from such policies as dismissal protection for regular workers and the stricter regulation of flexible work arrangements. Furthermore, the dynamics of labour adjustment in the German sample is largely determined by this process. In contrast to Germany, labour adjustment in the Netherlands is also highly responsive to wages. These results reflect that adjustment to employment is more flexible in the Netherlands. Thirdly, there is no evidence that factor adjustment is interrelated as the coefficients on the interrelation terms are often insignificant, and in each case of negligible magnitude. Thus, we find no indication that the differences in the labour markets between the two countries are reflected in the investment dynamics. Finally, although controlling for selection bias leads to multicollinearity in the Dutch case, there is no indication that endogenous sample selection alters the main conclusions. 


\section{References}

Abel, A., And J. EBerly (2001): "Investment and Q with Fixed Costs: An Empirical Analysis," Working Paper.

Aguirregabiria, V. (1997): "Estimation of Dynamic Programming Models with Censored Dependent Variables," Investigaciones Economicas, 21(2), 167208.

Alonso-Borrego, C. (1998): "Demand for Labour Inputs and Adjustment Costs: Evidence from Spanish Manufacturing Firms," Labour Economics, 5, 475-497.

Arellano, M., And S. Bond (1991): "Some Tests of Specification for Panel Data: Monte Carlo Evidence and an Application to Employment Equations.," Review of Economic Studies, 58, 277-297.

Arellano, M., And O. Bover (1995): "Another Look at the InstrumentalVariable Estimation of Error-Components Models," Journal of Econometrics, $68,29-52$.

BARnett, S., AND P. SAKellaris (1998): "Nonlinear Response of Firm Investment to Q: Testing a Model of Convex and Non-Convex Adjustment Costs," Journal of Monetary Economics, 42, 261-288.

Bertola, G. (1999): "Microeconomic Perspectives on Aggregate Labor Markets," in Handbook of Labor Economics, ed. by O. Ashenfelter, and D. Card, vol. 3, pp. 2985-3028. Elsevier Science.

Blundell, R., And S. Bond (1998): "Initial Conditions and Moment Restrictions in Dynamic Panel Data Models," Journal of Econometrics, 87, 115-143.

Bond, S., And C. Meghir (1994): "Dynamic Investment Models and Firm's Financial Policy," Review of Economic Studies, 61, 197-222.

Bond, S., And J. VAn Reenen (2002): "Microeconometric Models of Investment and Employment," Working Paper. 
Cooper, R., J. Haltiwanger, and L. Power (1999): "Machine Replacement and the Business Cycle: Lumps and Bumps," American Economic Review, 89(4), 921-946.

Delsen, L., And E. De Long (eds.) (1998): The German and Dutch Economies: Who Follows Whom? Physica-Verlag, Heidelberg, Germany.

Dixit, A. (1997): "Investment and Employment Dynamics in the Short Run and the Long Run," Oxford Economic Papers, 49, 1-20.

Doornik, J. (2002): Object-Oriented Matrix Programming Using Ox. Timberlake Consultants Press, London, 3rd edn.

Doornik, J., M. Arellano, and S. Bond (2002): "Panel Data Estimation Using DPD for Ox," DPD Package Manual.

Eberly, J., And J. V. Mieghem (1997): "Multi-Factor Dynamic Investment under Uncertainty," Journal of Economic Theory, 75, 345-387.

Eisner, R., And R. Strotz (1963): "Determinants of Investment Behavior," in Impacts of Monetary Policy, ed. by R. Eisner, and R. Strotz, pp. 59-223. Prentice-Hall, Englewood Cliffs, NJ.

Hamermesh, D. (1989): "Labor Demand and the Structure of Adjustment Costs," American Economic Review, 79(4), 674-689.

Hamermesh, D., and G. Pfann (1996): "Adjustment Costs in Factor Demand," Journal of Economic Literature, 34, 1264-1292.

Hansen, L. (1982): "Large Sample Properties of Generalized Method of Moments Estimators," Econometrica, 50(4), 1029-1054.

Heckman, J. (1979): "Sample Selection Bias as a Specification Error," Econometrica, 47, 153-161.

Hoogduin, L., and H. Huisman (1998): "The Financial Structure in the Netherlands and Germany: Different, Harmonious, and on the Move?," in The German and Dutch Economies: Who Follows Whom?, ed. by L. Delsen, and E. de Jong. Physica-Verlag, Heidelberg, Germany. 
Janz, N., G. Ebling, S. Gottschalk, and H. Niggemann (2001): "The Mannheim Innovation Panels (MIP and MIP-S) of the Centre for European Economic Research (ZEW)," Schmollers Jahrbuch, 121, 123-129.

Letterie, W., and G. Pfann (2003): "On the Identification of High and Low Regimes in Equipment Investment Expenditures of Firms," Working Paper.

Letterie, W., G. Pfann, and J. Polder (2004): "Factor adjustment spikes and interrelation: an empirical investigation," forthcoming in Economics Letters.

Merz, M., And E. Yashiv (2003): "Labor and the Market Value of the Firm," IZA Discussion Paper, 965.

Nadiri, M., and S. Rosen (1969): "Interrelated Factor Demand Functions," American Economic Review, 59(4), 457-471.

Nilsen, O., and F. Schiantarelli (2003): "Zeros and Lumps in Investment: Empirical Evidence on Irreversibilities and Nonconvexities," Review of Economics and Statistics, 85, 1021-1037.

OECD (1999): "Employment Protection and Labour Market Performance," in OECD Employment Outlook, pp. 45-132. OECD, Paris.

Pfann, G., and F. Palm (1993): "Asymmetric Adjustment Costs in NonLinear Labour Demand Models for the Netherlands and U.K. Manufacturing Sectors," Review of Economic Studies, 60(2), 397-412.

Sakellaris, P. (2004): "Patterns of plant adjustment," Journal of Monetary Economics, 51, 425-450.

Shapiro, M. (1986): "The Dynamic Demand for Capital and Labor," Quarterly Journal of Economics, 101(3), 513-542.

WindmeiJer, F. (2000): "A Finite Sample Correction for the Variance of Linear Two-Step GMM Estimators," IFS Working Paper, 00/19. 


\section{A Appendix}

Table 1: Macroeconomic Indicators

\begin{tabular}{|c|c|c|c|c|c|c|c|c|c|}
\hline & 1992 & 1993 & 1994 & 1995 & 1996 & 1997 & 1998 & 1999 & 2000 \\
\hline \multicolumn{10}{|c|}{ Growth rate of GDP at market prices (\%) } \\
\hline Germany & 2.2 & -1.1 & 2.4 & 1.7 & 0.8 & 1.4 & 2.0 & 1.9 & 3.0 \\
\hline Netherlands & 1.7 & 0.9 & 2.6 & 2.9 & 3.0 & 3.8 & 4.3 & 3.7 & 3.5 \\
\hline \multicolumn{10}{|c|}{ Growth rate of production in industry excl. construction (\%) } \\
\hline Germany & -2.2 & -8.0 & 3.3 & 0.8 & 0.6 & 3.6 & 4.2 & 1.5 & 6.7 \\
\hline Netherlands & $-\mathrm{b}$ & - & - & - & 2.4 & 0.2 & 2.4 & 2.2 & 2.9 \\
\hline \multicolumn{10}{|c|}{ Growth rate of employment in industry excl. construction (\%)c } \\
\hline Germany & -10.2 & -8.8 & -6.5 & -4.0 & -3.8 & -3.2 & -0.3 & -0.8 & -0.1 \\
\hline Netherlands & -0.8 & -3.7 & -2.8 & -0.4 & -0.7 & 1.3 & 1.3 & 0.4 & 0.3 \\
\hline
\end{tabular}

${ }^{\mathrm{a}}$ Working days adjusted

b Data missing for 1992-1995

c Gross employment

Source: Eurostat Yearbook 2002 
Table 2: Summary Statistics

\begin{tabular}{lcccccc}
\hline & \multicolumn{3}{c}{ Germany } & \multicolumn{3}{c}{ Netherlands } \\
\hline Variable & Mean & Std. Dev. & Median & Mean & Std. Dev. & Median \\
\hline \hline Total investment $^{\mathrm{a}}$ & 8.04 & 55.79 & 0.80 & 2.9 & 27 & 0.44 \\
Employment & 474 & 1997 & 91 & 151 & 807 & 61 \\
Turnover/Sales $^{\mathrm{a}}$ & 148.55 & 713.48 & 17 & 59.4 & 293 & 14.5 \\
$I / K$ & 0.180 & 0.186 & 0.125 & 0.068 & 0.083 & 0.044 \\
$H / L$ & -0.015 & 0.204 & 0 & -0.013 & 0.142 & 0 \\
$Y / K^{\mathrm{b}}$ & 6.521 & 18.925 & 3.026 & 2.573 & 8.571 & 1.399 \\
$Y / L^{\mathrm{c}}$ & 253.38 & 428.17 & 179.72 & 311.74 & 405.79 & 226.08 \\
Wage $^{\mathrm{c}}$ & 62.825 & 39.563 & 59.593 & 63.360 & 20.058 & 62.267 \\
\hline No. of Obs. & 18147 & & & 25109 & & \\
\hline \hline
\end{tabular}

${ }^{a}$ Millions of DMs for German firms; millions of Guilders for Dutch firms.

b Real sales per unit of capital stock

c Thousands of DMs and Guilders per worker for German and Dutch firms, respectively.

Source: German data - ZEW Mannheim Innovation Panel 1992-2000, Dutch data

- CEREM, Statistics Netherlands (CBS) 1992-2000. 


\section{Table 3: Censoring of Investment and Labour Adjustment Rates}

\begin{tabular}{cccc}
\hline \hline & & Germany & Netherlands \\
\hline \hline \# periods & $\%$ & $\%$ \\
\hline$H / L=0$ & 1 & 9.75 & 4.23 \\
& 2 & 10.04 & 6.14 \\
\hline \hline
\end{tabular}

Source: German data - ZEW Mannheim Innovation Panel 1992-2000, Dutch data - CEREM, Statistics Netherlands (CBS) 1992-2000

Table 4: Adjustment Regimes

\begin{tabular}{ccc}
\hline \hline & $\begin{array}{c}\text { Germany } \\
\%\end{array}$ & $\begin{array}{c}\text { Netherlands } \\
\%\end{array}$ \\
\hline \hline$\frac{I}{K}>0 \& \frac{H}{L} \neq 0$ & 79.33 & 80.52 \\
$\frac{I}{K}>0 \& \frac{H}{L}>0$ & 38.22 & 36.62 \\
$\frac{I}{K}>0 \& \frac{H}{L}<0$ & 41.12 & 43.89 \\
$\frac{I}{K}>0 \& \frac{H}{L}=0$ & 14.15 & 15.47 \\
$\frac{I}{K}=0 \& \frac{H}{L} \neq 0$ & 5.19 & 3.11 \\
$\frac{I}{K}=0 \& \frac{H}{L}>0$ & 2.01 & 1.07 \\
$\frac{I}{K}=0 \& \frac{H}{L}<0$ & 3.19 & 2.03 \\
$\frac{I}{K}=0 \& \frac{H}{L}=0$ & 1.31 & 1.00 \\
\hline \hline
\end{tabular}

Source: German data - ZEW Mannheim Innovation Panel 1992-2000, Dutch data - CEREM, Statistics Netherlands (CBS) 1992-2000 
Table 5: GMM - Investment

\begin{tabular}{lcccc}
\hline \hline \multicolumn{5}{l}{ Dependent variable: $(I / K)_{i t}$} \\
& \multicolumn{2}{c}{ Germany } & \multicolumn{2}{c}{ Netherlands } \\
Variable & $(1)$ & $(2)$ & $(3)$ & $(4)$ \\
\hline \hline$(I / K)_{i, t-1}$ & Coefficient & Coefficient & Coefficient & Coefficient \\
& $0.404^{* * *}$ & $0.411^{* * *}$ & $0.111^{* *}$ & 0.064 \\
$(I / K)_{i, t-1}^{2}$ & $(0.091)$ & $(0.092)$ & $(0.052)$ & $(0.067)$ \\
& $-0.386^{* * *}$ & $-0.446^{* * *}$ & -0.150 & -0.142 \\
$(Y / K)_{i, t-1}$ & $(0.118)$ & $(0.152)$ & $(0.150)$ & $(0.141)$ \\
& $0.005^{* * *}$ & $0.003^{* *}$ & $0.007^{* * *}$ & 0.002 \\
$p_{i t}$ & $(0.002)$ & $(0.001)$ & $(0.002)$ & $(0.004)$ \\
& 0.032 & 0.021 & $-0.003^{* *}$ & $-0.013^{*}$ \\
$p_{i, t-1}$ & $(0.055)$ & $(0.033)$ & $(0.001)$ & $(0.007)$ \\
& -0.032 & -0.021 & $0.012^{* *}$ & 0.037 \\
$H_{i t}$ & $(0.056)$ & $(0.033)$ & $(0.006)$ & $(0.024)$ \\
& $-4.37 \mathrm{e}-08$ & $3.71 \mathrm{e}-04$ & $-1.04 \mathrm{e}-05$ & $3.293 \mathrm{e}-04$ \\
$H_{i, t-1}$ & $(7.35 \mathrm{e}-06)$ & $(3.17 \mathrm{e}-04)$ & $(1.53 \mathrm{e}-05)$ & $(0.0002)$ \\
& $5.99 \mathrm{e}-07$ & $1.04 \mathrm{e}-04$ & $5.41 \mathrm{e}-06^{*}$ & $5.082 \mathrm{e}-05$ \\
$\lambda_{i t}^{I}$ & $(1.00 \mathrm{e}-005)$ & $(1.05 \mathrm{e}-004)$ & $(3.00 \mathrm{e}-006)$ & $(6.323 \mathrm{e}-05)$ \\
& & 0.007 & & -0.018 \\
& & $(0.032)$ & & $(0.040)$ \\
\hline Instruments ${ }^{a}$ & $t-2, t-3$ & $t-2-t-4$ & $t-2, t-3$ & $t-2, t-3$ \\
Sargan test & 44.33 & 53.19 & 70.90 & 79.35 \\
AR(1) test & $-6.008^{* * *}$ & $-4.513^{* * *}$ & $-11.99^{* * *}$ & $-4.650^{* * *}$ \\
AR(2) test & -0.440 & -1.448 & 1.375 & -0.357 \\
\hline No. of Obs. & 2646 & 1792 & 8799 & 5420 \\
\hline \hline
\end{tabular}

Source: German data - ZEW Mannheim Innovation Panel 1992-2000; Dutch data - CEREM, Statistics Netherlands (CBS) 1992-2000. Two-step results from the Blundell-Bond GMM Estimator are reported. ${ }^{* * *}$ - Significant at 1\%, ${ }^{* *}$ - at $5 \%$, and ${ }^{*}-10 \%$ level. $I / K$ is the investment rate, $Y / K$ is the sales-capital ratio (real sales per unit of capital stock), $p$ is the price of investment goods, and $L$ is the employment level. Specifications for both countries include year dummies and a dummy for East Germany is included in the German specification. $a$ Instruments in levels for transformed equations: German sample $-I / K, I / K^{2}$, and $Y / K$; Dutch sample $-I / K, I / K^{2}, Y / K, \Delta L$, and current and lagged $p$. Instruments in differences for level equations: German sample - $I / K, I / K^{2}, Y / K$, and dummies; Dutch sample - $I / K, I / K^{2}, Y / K, \Delta L$, and dummies. 


\section{Table 6: GMM - Labour Adjustment}

\begin{tabular}{|c|c|c|c|c|}
\hline \multicolumn{5}{|c|}{ Dependent variable: $(H / L)_{i t}$} \\
\hline & \multicolumn{2}{|c|}{ Germany } & \multicolumn{2}{|c|}{ Netherlands } \\
\hline & (1) & $(2)$ & $(3)$ & (4) \\
\hline Variable & Coefficient & Coefficient & Coefficient & Coefficient \\
\hline \multirow{2}{*}{$(H / L)_{i, t-1}$} & $-0.133^{*}$ & $-0.160 * *$ & $0.066^{* *}$ & 0.021 \\
\hline & $(0.069)$ & $(0.078)$ & $(0.031)$ & $(0.024)$ \\
\hline \multirow{2}{*}{$(H / L)_{i, t-1}^{2}$} & -0.083 & -0.069 & 0.103 & 0.021 \\
\hline & $(0.140)$ & $(0.157)$ & $(0.074)$ & $(0.055)$ \\
\hline \multirow{2}{*}{$(Y / L)_{i, t-1}$} & $1.21 \mathrm{e}-05$ & $1.03 \mathrm{e}-06$ & $3.52 \mathrm{e}-0.5$ & $4.62 \mathrm{e}-05^{* *}$ \\
\hline & $(2.85 \mathrm{e}-05)$ & $(2.28 \mathrm{e}-05)$ & $(2.51-05)$ & $(1.94 \mathrm{e}-05)$ \\
\hline \multirow[t]{2}{*}{$w_{i t}$} & $1.74 \mathrm{e}-04$ & $3.78 \mathrm{e}-04$ & $-0.006^{* * *}$ & $-0.005^{* * *}$ \\
\hline & $(5.90 \mathrm{e}-04)$ & $(6.40 \mathrm{e}-04)$ & $(0.000)$ & $(4.70 \mathrm{e}-04)$ \\
\hline \multirow[t]{2}{*}{$w_{i, t-1}$} & $3.52 \mathrm{e}-04$ & $4.41 \mathrm{e}-04$ & $0.004^{* * *}$ & $0.004^{* * *}$ \\
\hline & $(3.25 \mathrm{e}-04)$ & $(3.72 \mathrm{e}-04)$ & $(0.001)$ & $(0.001)$ \\
\hline \multirow[t]{2}{*}{$I_{i t}$} & $-9.15 \mathrm{e}-07^{*}$ & $-7.29 \mathrm{e}-07^{*}$ & $-7.71 \mathrm{e}-08$ & $-7.84 \mathrm{e}-08$ \\
\hline & $(4.78 \mathrm{e}-07)$ & $(5.08 \mathrm{e}-07)$ & $(7.26 \mathrm{e}-08)$ & $(7.42 \mathrm{e}-08)$ \\
\hline \multirow[t]{2}{*}{$I_{i, t-1}$} & $1.71 \mathrm{e}-06$ & $1.30 \mathrm{e}-06$ & $1.05 \mathrm{e}-07^{* *}$ & $7.43 \mathrm{e}-08 * *$ \\
\hline & $(1.05 \mathrm{e}-06)$ & $(1.12 \mathrm{e}-06)$ & $(4.60 \mathrm{e}-08)$ & $(3.41 \mathrm{e}-08)$ \\
\hline \multirow[t]{2}{*}{$\lambda_{i t}^{H}$} & & 0.021 & & $-0.031^{* * *}$ \\
\hline & & $(0.024)$ & & $(0.010)$ \\
\hline Instruments $^{a}$ & $t-2, t-3$ & $t-2, t-3$ & $t-2, t-3$ & $t-2, t-3$ \\
\hline Sargan test & 62.37 & 62.90 & $182.6^{* * *}$ & $126.0 * * *$ \\
\hline $\mathrm{AR}(1)$ test & $-4.229^{* * *}$ & $-3.956^{* * *}$ & $-12.56^{* * *}$ & $-12.43^{* * *}$ \\
\hline $\mathrm{AR}(2)$ test & -1.197 & -1.038 & 0.527 & -1.005 \\
\hline No. of Obs. & 1402 & 1291 & 11659 & 8517 \\
\hline
\end{tabular}

Source: German data - ZEW Mannheim Innovation Panel 1992-2000; Dutch data - CEREM, Statistics Netherlands (CBS) 1992-2000. Two-step results from the Blundell-Bond GMM Estimator are reported. $H / L$ is the labour adjustment rate such that $H_{t}=L_{t}-L_{t-1}, Y / L$ is the sales per worker ratio, $w$ is the average per-worker wage, and $I$ is investment (in thousands of DM/GLD) deflated by the price index for capital goods. Specifications for both countries include year dummies and a dummy for East Germany is included in the German specification. $a$ - Instruments in levels for transformed equations: $H / L, H / L^{2}, Y / L, w$, and $I$. Instruments in differences for level equations: $H / L, H / L^{2}, Y / L, w, I$, and dummies. 


\section{Table 7: Two-period Selection - Investment}

\begin{tabular}{|c|c|c|}
\hline \multicolumn{3}{|c|}{ "Dependent variable: $\mathcal{I}\left((I / K)_{i t} \neq 0 \&(I / K)_{i, t-1} \neq 0\right)$} \\
\hline & $\begin{array}{c}\text { Germany } \\
(1)\end{array}$ & $\begin{array}{c}\text { Netherlands } \\
\text { (2) }\end{array}$ \\
\hline Variable & Coefficient & Coefficient \\
\hline$\overline{(I / K)_{i, t-1}}$ & $\begin{array}{c}10.723^{* * *} \\
(0.893)\end{array}$ & $\begin{array}{c}13.672^{* * *} \\
(0.926)\end{array}$ \\
\hline$(I / K)_{i, t-1}^{2}$ & $\begin{array}{c}-13.080 * * * \\
(1.189)\end{array}$ & $\begin{array}{c}-23.842^{* * *} \\
(1.834)\end{array}$ \\
\hline$(Y / K)_{i, t-1}$ & $\begin{array}{c}-0.0564^{* * *} \\
(0.011)\end{array}$ & $\begin{array}{c}-0.056^{* * *} \\
(0.016)\end{array}$ \\
\hline$p_{i t}$ & $\begin{array}{l}0.089^{*} \\
(0.046)\end{array}$ & $\begin{array}{c}0.042 \\
(0.027)\end{array}$ \\
\hline$p_{i, t-1}$ & $\begin{array}{l}- \\
(-)\end{array}$ & $\begin{array}{c}0.033 \\
(0.043)\end{array}$ \\
\hline$H_{i t}$ & $\begin{array}{c}2.76 \mathrm{e}-05 \\
(5.62 \mathrm{e}-04)\end{array}$ & $\begin{array}{c}4.24 \mathrm{e}-05 \\
(3.24 \mathrm{e}-04)\end{array}$ \\
\hline$H_{i, t-1}$ & $\begin{array}{c}3.61 \mathrm{e}-04 \\
(3.36 \mathrm{e}-04)\end{array}$ & $\begin{array}{l}-0.001 \\
(0.001)\end{array}$ \\
\hline$(I / K)_{i, t-2}$ & $\begin{array}{c}0.830 \\
(0.731)\end{array}$ & $\begin{array}{c}1.643^{* * *} \\
(0.621)\end{array}$ \\
\hline$(I / K)_{i, t-2}^{2}$ & $\begin{array}{c}-2.504^{* *} \\
(0.990)\end{array}$ & $\begin{array}{c}-2.978^{* * *} \\
(0.941)\end{array}$ \\
\hline$(Y / K)_{i, t-2}$ & $\begin{array}{c}0.017^{* *} \\
(0.007)\end{array}$ & $\begin{array}{l}-0.005 \\
(0.016)\end{array}$ \\
\hline$p_{i, t-2}$ & $\begin{array}{l}- \\
(-)\end{array}$ & $\begin{array}{c}-0.063^{* *} \\
(0.031)\end{array}$ \\
\hline$\Delta L_{i, t-2}$ & $\begin{array}{l}-1.70 \mathrm{e}-04 \\
(2.97 \mathrm{e}-04)\end{array}$ & $\begin{array}{c}-1.56 \mathrm{e}-04 \\
(3.571 \mathrm{e}-04)\end{array}$ \\
\hline No. of Obs. & 2255 & 7688 \\
\hline Log Likelihood & -483.569 & -1359.87 \\
\hline
\end{tabular}

Source: German data - ZEW Mannheim Innovation Panel 1992-2000; Dutch data - CEREM, Statistics Netherlands (CBS) 1992-2000. Each selection equations is estimated as a probit model. $I / K$ is the investment rate, $Y / K$ is the sales-capital ratio (real sales per unit of capital stock), $p$ is the price of investment goods, and $L$ is the employment level. Specifications for both countries include year dummies and a dummy for East Germany is included in the German specification. $\mathcal{I}$ is an indicator variable and equals 1 if the condition inside the parentheses is fulfilled and 0 otherwise. Standard errors are reported in parentheses. 


\section{Table 8: Two-period Selection - Labour Adjustment}

\begin{tabular}{|c|c|c|}
\hline \multicolumn{3}{|c|}{ Dependent variable: $\mathcal{I}\left((H / L)_{i t} \neq 0 \&(H / L)_{i, t-1} \neq 0\right)$} \\
\hline \multirow[b]{2}{*}{ Variable } & $\begin{array}{l}\text { Germany } \\
\text { (1) }\end{array}$ & $\begin{array}{c}\text { Netherlands } \\
\text { (2) }\end{array}$ \\
\hline & Coefficient & Coefficient \\
\hline \multirow[t]{2}{*}{$\overline{(H / L)_{i, t-1}}$} & $0.634^{* * *}$ & $0.800^{* * *}$ \\
\hline & $(0.236)$ & $(0.139)$ \\
\hline \multirow[t]{2}{*}{$(H / L)_{i, t-1}^{2}$} & $2.085^{* * *}$ & $3.311^{* * *}$ \\
\hline & $(0.486)$ & $(0.329)$ \\
\hline \multirow[t]{2}{*}{$(Y / L)_{i, t-1}$} & $4.90 \mathrm{e}-04$ & $1.39 \mathrm{e}-04$ \\
\hline & $(4.71 \mathrm{e}-04)$ & $(1.24 \mathrm{e}-04)$ \\
\hline \multirow[t]{2}{*}{$w_{i t}$} & $4.75 \mathrm{e}-04$ & $0.004^{* *}$ \\
\hline & $(0.013)$ & $(0.002)$ \\
\hline \multirow[t]{2}{*}{$w_{i, t-1}$} & 0.002 & $0.005^{* *}$ \\
\hline & $(0.001)$ & $(0.002)$ \\
\hline \multirow[t]{2}{*}{$I_{i t}$} & $-4.92 \mathrm{e}-06$ & $1.70 \mathrm{e}-05^{* * *}$ \\
\hline & $(5.08 \mathrm{e}-06)$ & $(2.00 \mathrm{e}-06)$ \\
\hline \multirow[t]{2}{*}{$I_{i, t-1}$} & $-1.61 \mathrm{e}-06$ & $-1.00 \mathrm{e}-06^{* * *}$ \\
\hline & $(7.73 \mathrm{e}-06)$ & $(4.23 \mathrm{e}-07)$ \\
\hline \multirow[t]{2}{*}{$(H / L)_{i, t-2}$} & 0.030 & $0.220^{* *}$ \\
\hline & $(0.179)$ & $(0.102)$ \\
\hline \multirow[t]{2}{*}{$(H / L)_{i, t-2}^{2}$} & -0.162 & 0.255 \\
\hline & $(0.357)$ & $(0.204)$ \\
\hline \multirow[t]{2}{*}{$(Y / L)_{i, t-2}$} & $-9.08 \mathrm{e}-04^{*}$ & -0.001 \\
\hline & $(4.84 \mathrm{e}-04)$ & $(0.001)$ \\
\hline \multirow[t]{2}{*}{$w_{i, t-2}$} & $0.004^{*}$ & -0.002 \\
\hline & $(0.002)$ & $(0.002)$ \\
\hline \multirow[t]{2}{*}{$I_{i, t-2}$} & $4.24 \mathrm{e}-04^{* * *}$ & $-1.00 \mathrm{e}-06$ \\
\hline & $(8.93 \mathrm{e}-06)$ & $(4.24 \mathrm{e}-07)$ \\
\hline No. of Obs. & 2417 & 11842 \\
\hline Log Likelihood & -1381.701 & -7170.526 \\
\hline
\end{tabular}

Source: German data - ZEW Mannheim Innovation Panel 1992-2000; Dutch data - CEREM, Statistics Netherlands (CBS) 1992-2000. Each selection equations is estimated as a probit model. $H / L$ is the labour adjustment rate such that $H_{t}=L_{t}-L_{t-1}, Y / L$ is the sales per worker ratio, $w$ is the average per-worker wage, and $I$ is investment (in thousands of DM/GLD) deflated by the price index for capital goods. Specifications for both countries include year dummies and a dummy for East Germany is included in the German specification. $\mathcal{I}$ is an indicator variable and equals 1 if the condition inside the parentheses is fulfilled and 0 otherwise. Standard errors are reported in parentheses. 
Figure 1: Distribution of Investment Rate (I/K) - Germany

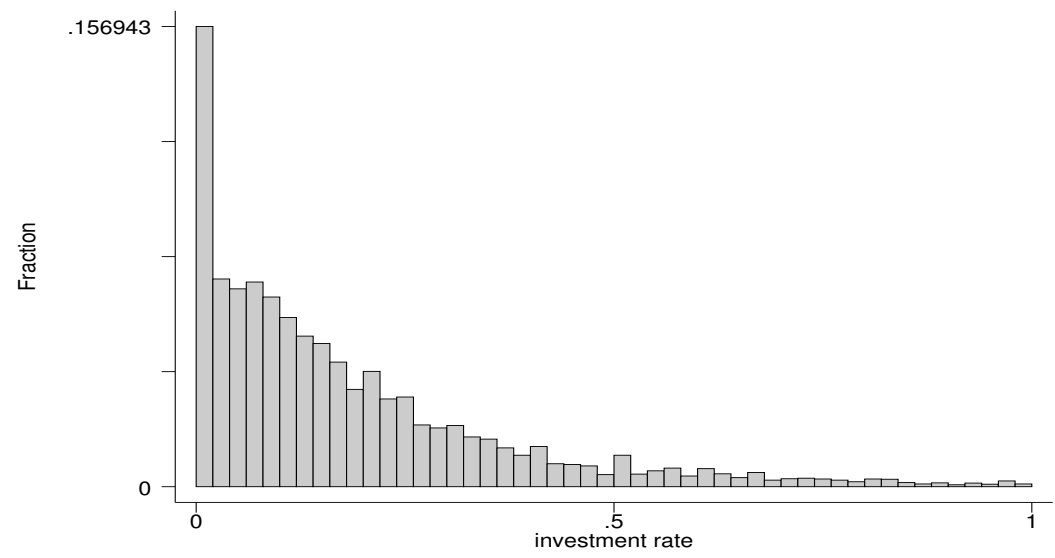

Source: ZEW Mannheim Innovation Panel 1992-2000

Figure 2: Distribution of Investment Rate (I/K) - Netherlands

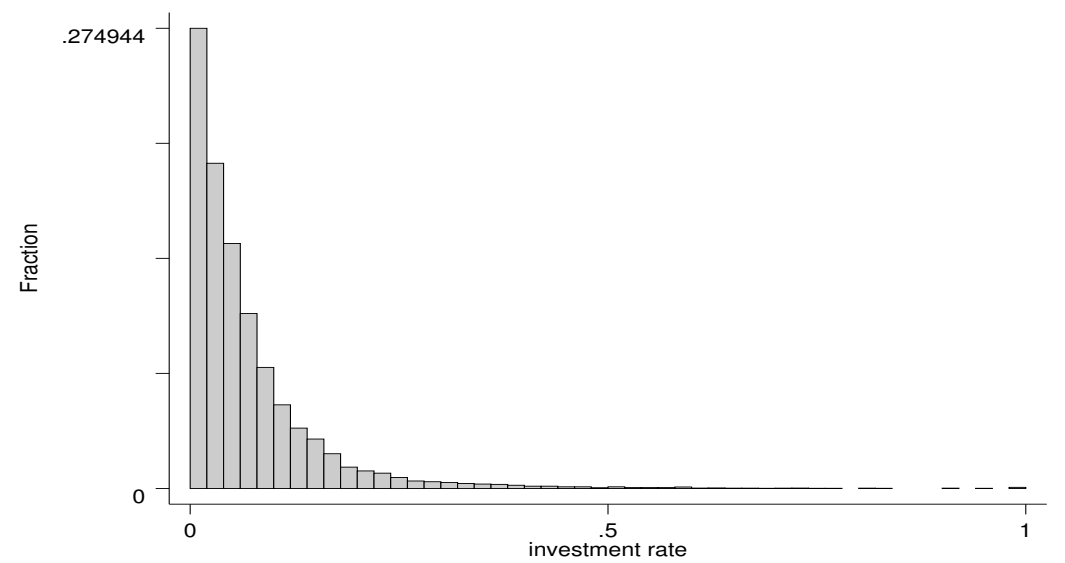

Source: CEREM, Statistics Netherlands (CBS) 1992-2000 
Figure 3: Distribution of Labour Adjustment Rate (H/L) - Germany

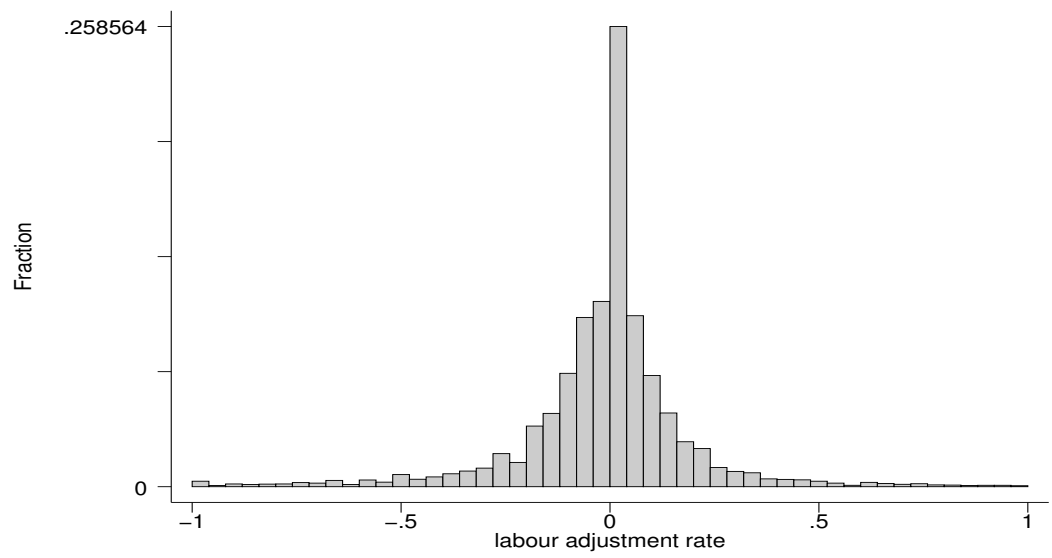

Source: ZEW Mannheim Innovation Panel 1992-2000

Figure 4: Distribution of Labour Adjustment Rate (H/L) - Netherlands

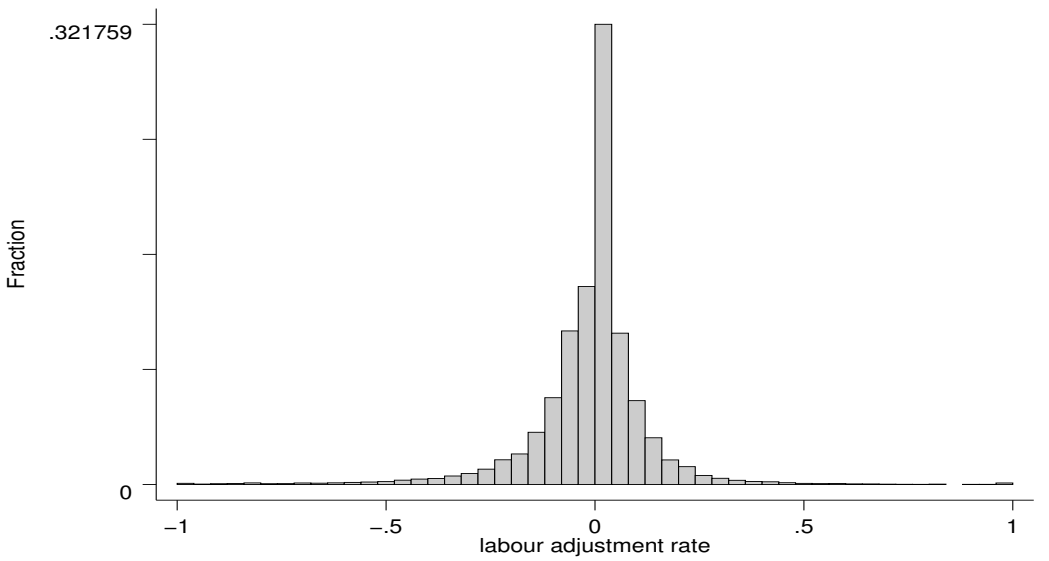

Source: CEREM, Statistics Netherlands (CBS) 1992-2000 